\title{
Gene Expression Profiling from a Prostate Cancer PC-3 Cell Line Treated with Salinomycin Predicts Cell Cycle Arrest and Endoplasmic Reticulum Stress
}

\section{Kwang-Youn Kim"\#, Young-Kyo Seo"\#, Sun-Nyoung Yu', Sang-Hun Kim¹, Pann-Ghill Suh², Jae-Hoon Ji, Hak-Sun Yu, Yeong-Min Park and Soon-Cheol Ahn ${ }^{1,5 *}$}

${ }^{1}$ Department of Microbiology \& Immunology, Pusan National University School of Medicine, Yangsan 626-870, Republic of Korea

${ }^{2}$ School of NanoBioscience and Chemical Engineering, Ulsan National Institute of Science and Technology,

Ulsan 689-798, Republic of Korea

${ }^{3}$ Genome Instability Research Center, Ajou University School of Medicine, Suwon 443-721, Republic of Korea

${ }^{4}$ Department of Parasitology, Pusan National University School of Medicine, Yangsan 626-870, Republic of Korea

${ }^{5}$ Medical Research Institute, Pusan National University, Yangsan 626-870, Republic of Korea

\#These authors contributed equally to this work

\begin{abstract}
Previously, we reported that salinomycin induces apoptosis of human prostate cancer cells through accumulated reactive oxygen species and mitochondrial membrane depolarization. To extend our understanding for the genomewide expression pattern, we performed cDNA microarray analysis for gene expression profiles in prostate PC-3 cells treated with salinomycin. We found a couple of differences from gene expression profiles. First of them, cyclins and cyclin-dependent kinases were down-regulated, whereas cyclin dependent kinase inhibitors were upregulated, implicating inhibition of cell cycle progression. Second, HSPA5/Bip, DDIT3/CHOP, TRIB3, ATF4 and ATF6 regarding endoplasmic reticulum (ER) stress and unfolded protein response (UPR) were increased at mRNA and protein levels, indicating salinomycin-induced growth inhibition of PC-3 cells seem to be mediated through induction of ER stress and activation of the UPR pathway. Our finding should be useful for understanding genomewide expression patterns of salinomycin-mediated cell cycle arrest and ER stress response toward induction of apoptosis and be helpful for finding future cancer therapeutic targets in prostate cancer cells.
\end{abstract}

Keywords: Salinomycin; Prostate cancer; Apoptosis; Cell cycle; Proliferation; Endoplasmic reticulum stress; Gene expression analysis

\section{Introduction}

As of 2011, prostate cancer is the most frequently diagnosed cancer and the sixth leading cause of cancer death in males worldwide. Rates of detection of prostate cancers vary widely across the world, with South and East Asia detecting less frequently than in Europe and especially the United States [1]. Pharmacologic inhibition of the androgen receptor (AR) pathway by depletion of circulating androgen and by anti-AR drugs is a regular treatment as standard care, which induces apoptosis in androgen-dependent prostate cancer cells and brings the disease to remission. However, most hormone dependent cancers become refractory after one to three years and therapy resistance to conventional chemotherapy for a limited period. Thus finding new treatment options for therapy-resistant prostate cancer has been a critical challenge [2].

The complex network of cell cycle and apoptosis are closely linked $[3,4]$. Treatment of cancer cells with anticancer agents usually results in the arrest of the cell cycle, the cells subsequently entering into apoptosis. Checkpoint signaling may also result in activation of pathways leading to apoptosis if cellular damage cannot be properly repaired [5]. $G_{1}$ phase cyclin/cyclin-dependent kinase (CDK) complexes play a key role in the $\mathrm{G}_{1} / \mathrm{S}$ checkpoint function. Three D type cyclins (cyclin D1, D2 and D3) bind to CDK4 and CDK6, which are essential for entry into $\mathrm{G}_{1}$ phase [6]. Also cyclin $\mathrm{E}$ associated with $\mathrm{CDK} 2$ regulates progression from $\mathrm{G}_{1}$ into $\mathrm{S}$ phase [7]. CDKs are negatively regulated by a group of functionally-related proteins, CDK inhibitors [8,9]. In recent studies, one of CDK inhibitors, $\mathrm{p} 21^{\mathrm{Cip} 1}$ cleavage is a critical step in converting to growth arrest and apoptosis of cancer cells $[10,11]$.
The main functions of endoplasmic reticulum (ER) are protein synthesis, folding, lipid synthesis and maintenance of $\mathrm{Ca}^{2+}$ homeostasis [12]. Conditions interfering with the function of ER, such as accumulation of unfolded proteins (unfolded protein response, UPR) and excessive protein traffic (ER overload response, EOR), are collectively called ER stress. The purpose of UPR is to restore normal function and activate the signaling pathway, but apoptotic cascade will be activated during prolonged or irresistible ER stress [13]. During ER stress, one of the three ER stress sensors; eukaryotic translation initiation factor 2 alpha (eIF2- $\alpha$ ) kinase 3 (EIF2AK3/PERK) is a serine/ threonine protein kinase and is activated by ER stress via dimerization and autophosphorylation upon the dissociation with Bip. Activated PERK phosphorylates eIF2 $\alpha$, thereby attenuating global protein synthesis to reduce the protein load of ER [14]. However, translation of certain mRNAs is allowed, like mRNAs for activating transcription factor 4 (ATF4) and its downstream target C/EBP-homologous protein (CHOP) [15,16]. CHOP, which is also regulated by $\mathrm{X}$-box binding protein 1 (XBP-1) [17], promotes apoptosis by down-regulating anti-

*Corresponding author: Soon-Cheol Ahn, Professor, Department of Microbiology \& Immunology, Pusan National University School of Medicine Yangsan 626-870, Republic of Korea, Tel: +82-51-510-8092; Fax: +82-55-3828090; E-mail: ahnsc@pusan.ac.kr

Received November 01, 2012; Accepted December 05, 2012; Published December 07, 2012

Citation: Kim KY, Seo YK, Yu SN, Kim SH, Suh PG, et al. (2013) Gene Expression Profiling from a Prostate Cancer PC-3 Cell Line Treated with Salinomycin Predicts Cell Cycle Arrest and Endoplasmic Reticulum Stress. J Cancer Sci Ther 5: 023 030. doi:10.4172/1948-5956.1000180

Copyright: (C) $2013 \mathrm{Kim} \mathrm{KY}$, et al. This is an open-access article distributed unde the terms of the Creative Commons Attribution License, which permits unrestricted use, distribution, and reproduction in any medium, provided the original author and source are credited. 
apoptotic factors like Bcl-2 [18] and up-regulating pro-apoptotic factors like the Bcl-2-interacting protein Bim [19].

Salinomycin is a monocarboxylic polyether antibiotic widely used as an anticoccidiosis agent in chickens [20,21]. A recent study showed that in high-throughput screening of $\sim 16,000$ small molecule chemicals, breast cancer stem cells (CSCs) were found to be inhibited selectively by salinomycin, showing at least 100 times more effective than paclitaxel in mice [22]. CSCs are a subpopulation of cells within the tumor mass that are thought to account for cancer recurrence by virtue of their refractivity to cytotoxic cancer treatment agents such as radiation and a wide variety of chemotherapeutic agents. Susceptibility of CSCs to salinomycin bolsters the possibility that this drug may target chemotherapy-resistant advanced human cancers. The mechanism of action by which salinomycin kills cancer stem cells specifically remains unknown. However, several studies show that the anticancer property of salinomycin has been recognized based on its ability to induce apoptosis and cause growth inhibition in diverse types of apoptosis and chemotherapeutic-resistant cancer cells [23]. In fact, salinomycin caused massive tumor cell apoptosis and associated regression of breast tumor growth and metastasis in vivo in a mouse xenograft tumor model [23]. This drug also triggers apoptosis by overcoming ABC transportermediated multidrug resistance, as was observed in the case of KG-1a human leukemia cells $[24,25]$. Description of the mechanisms that underlies cancer cell apoptosis by salinomycin is needed in order to rigorous assessment of the therapeutic potential of this drug as a novel cancer therapeutic.

Previously, we reported that proliferation of the androgendependent LNCaP and androgen-independent PC-3 prostate cancer cells markedly reduced in response to salinomycin treatment [26]. Its anti-proliferation resulted from induction of apoptosis through accumulated reactive oxygen species and mitochondrial membrane depolarization. In the present study, we have examined the mechanism that underlies prostate cancer cell death in the presence of salinomycin by gene expression using cDNA microarray. We present gene profiling for the first time that salinomycin-mediates cell cycle arrest and ER stress response for apoptosis of prostate cancer cells.

\section{Materials and Methods}

\section{Reagents and antibodies}

Salinomycin and Propidium iodide (PI) were purchased from Sigma Aldrich (St. Louis, MO, USA). The ECL Western Kit was purchased from Amersham (Arlington Heights, IL, USA). Antibodies for cyclin D1, cyclin E, CDK2, CDK6 and ATF4 were purchased from Santa Cruz Biotechnology (Santa Cruz, CA, USA). Antibodies for cyclin A, CDC2, p2 $1^{\text {cip1 }}$ IRE1 $\alpha$, Bip, and phospho-eIF2 $\alpha$ were purchased from Cell Signaling (Beverly, MS, USA). CDK4 and GADD153/CHOP were purchased from Stressgen (Victoria, BC, Canada) and USBiological (Swampscott, MA, USA), respectively.

\section{Cell lines and cell culture}

Androgen-independent PC-3 prostate cancer cells were obtained from the American Type Culture Collection (ATCC, Manassas, VA, USA). These cells were maintained and cultured in Dulbecco's modified Eagle's medium (DMEM; WelGENE Inc., Daegu, Korea) supplemented with 10\% fetal bovine serum (FBS) (WelGENE Inc.), 100 units $/ \mathrm{ml}$ of penicillin and $100 \mu \mathrm{g} / \mathrm{ml}$ of streptomycin (WelGENE Inc.). Cells were cultured in a humidified atmosphere with $5 \% \mathrm{CO}_{2}$ at $37^{\circ} \mathrm{C}$.

\section{Microarray analysis}

For control and salinomycin-treated RNAs, the synthesis of target cDNA probes and hybridization were performed using Agilent's Low RNA Input Linear Amplification kit (Agilent Technology, Santa Clara, CA, USA) according to the manufacturer's instructions. Briefly, each $0.2 \mu \mathrm{g}$ total RNA was mixed with the diluted Spike mix (A and B, Agilent Technology) and T7 promoter primer mix and incubated at $65^{\circ} \mathrm{C}$ for 10 min. cDNA master mix (5X First strand buffer, 0.1 M DTT, $10 \mathrm{mM}$ dNTP mix, RNase-Out, and MMLV-RT) was prepared and added to the reaction mixer. The samples were incubated at $40^{\circ} \mathrm{C}$ for $2 \mathrm{~h}$ and then the room temperature (RT) and dsDNA synthesis was terminated by incubating at $70^{\circ} \mathrm{C}$ for $10 \mathrm{~min}$. The transcription master mix was prepared as the manufacturer's protocol (4X Transcription buffer, $0.1 \mathrm{M}$ DTT, NTP mix, 50\% PEG, RNase-Out, Inorganic pyrophosphatase, T7-RNA polymerase, and Cyanine 3/5-CTP). Transcription of dsDNA was performed by adding the transcription master mix to the dsDNA reaction samples and incubating at $40^{\circ} \mathrm{C}$ for $2 \mathrm{~h}$. Amplified and labeled cRNA was purified on RNase mini column (Qiagen, Hamburg, Germany) according to the manufacturer's protocol. Labeled cRNA target was quantified using ND-1000 spectrophotometer (NanoDrop Technologies, Inc., Wilmington, DE, USA). After checking labeling efficiency, each $750 \mathrm{ng}$ of cyanine 3-labeled and cyanine 5-labeled cRNA target were mixed and the fragmentation of cRNA was performed by adding $10 \mathrm{X}$ blocking agent and $25 \mathrm{X}$ fragmentation buffer and incubating at $60^{\circ} \mathrm{C}$ for $30 \mathrm{~min}$. The fragmented cRNA was resuspended with $2 \mathrm{X}$ hybridization buffer and directly pipetted onto assembled Agilent Human Oligo microarray. The arrays hybridized at $65^{\circ} \mathrm{C}$ for $17 \mathrm{~h}$ using Agilent Hybridization oven (Agilent Technology). The hybridized miroarrays were washed as the manufacturer's washing protocol (Agilent Technology).

\section{Data acquisition and analysis}

The hybridization images were analyzed by Agilent DNA microarray Scanner (Agilent Technology) and the data quantification was performed using Agilent Feature Extraction software 9.3.2.1 (Agilent Technology). The average fluorescence intensity for each spot was calculated and local background was subtracted. All data normalization and selection of fold-changed genes were performed using GeneSpringGX 7.3.1 (Agilent Technology). Genes were filtered with removing flag-out genes in each experiment. Intensity-dependent normalization (LOWESS) was performed, where the ratio was reduced to the residual of the Lowess fit of the intensity vs. ratio curve. The averages of normalized ratios were calculated by dividing the average of normalized signal channel intensity by the average of normalized control channel intensity. $>2$ - fold changed genes were selected and considered as significant genes. Functional annotation of genes was performed according to DAVID Bioinformatics Resources 6.7 (http:// david.abcc.ncifcrf.gov/). All experiments have been submitted to Array-Express (EBML-EBI, Cambridge, UK).

\section{Cell cycle analysis}

PC-3 cells were plated in 6-well plates at a density of $1 \times 10^{5} /$ well for $24 \mathrm{~h}$ after serum starvation overnight. The culture medium was refreshed with new medium and then the cells were treated with various concentrations of salinomycin for $48 \mathrm{~h}$. And the cells were then fixed in $70 \%$ ethanol, washed with PBS twice and finally incubated in RNase A $(200 \mu \mathrm{g} / \mathrm{ml})$ at $37^{\circ} \mathrm{C}$ for $30 \mathrm{~min}$. DNA content per cell was evaluated in flow cytometer (Becton Dickinson Co., Franklin Lakes, NJ, USA) after staining cells with $1 \mathrm{mg} / \mathrm{ml}$ propidium iodide solution. Data collection 
Citation: Kim KY, Seo YK, Yu SN, Kim SH, Suh PG, et al. (2013) Gene Expression Profiling from a Prostate Cancer PC-3 Cell Line Treated with Salinomycin Predicts Cell Cycle Arrest and Endoplasmic Reticulum Stress. J Cancer Sci Ther 5: 023-030. doi:10.4172/1948-5956.1000180

and analysis of the cell cycle distribution were performed using Cell Quest and Modifit software (Becton Dickinson Co.).

\section{Semiquantitative Revers Transcriptase (RT)-PCR}

PC-3 cells were seeded in $60 \mathrm{~cm}^{2}$ cell culture dish $\left(1 \times 10^{6}\right.$ cells $)$. After $24 \mathrm{~h}$ incubation, cells were treated with salinomycin $(1.33$ $\mu \mathrm{M})$ for various times. Cell harvesting and total RNA isolation was performed using the RiboEX_column Total RNA purification Kit (GeneAll, Seoul, Korea). Semiquantitative RT-PCR amplification was performed using primers for CDKN2B, CDKN1C, CDKN2A, CCNB1, CCNB2, CCND1, CCND3, CCNE1, CDK2, HSPA5, DDIT3, TRIB3, ATF4, ATF6, XBP1 and GAPDH. RT-PCR primers were designed by primer 3 (http://frodo.wi.mit.edu) (Supplementary Table 1). For semiquantitative analysis, RT-PCR was performed at low cycle numbers to avoid saturation, in triplicate samples.

\section{Western blotting}

Cell extracts were prepared by incubating the cells in lysis buffer [150 mM NaCl, $10 \mathrm{mM}$ Tris (pH 7.4), 5 mM EDTA (pH 8.0), 1\% Triton X-100, $1 \mathrm{mM}$ PMSF, $20 \mathrm{mg} / \mathrm{ml}$ aprotinin, $50 \mu \mathrm{g} / \mathrm{ml}$ leupeptin, $1 \mathrm{mM}$ benzidine, and $1 \mathrm{mg} / \mathrm{ml}$ pepstatin]. Forty micrograms of proteins were electrophoretically separated using sodium dodecyl sulfate-polyacrylamide gel electrophoresis (SDS-PAGE) on a $12-15 \%$ gel and transferred to a polyvinylidenefluoride (PVDF) membrane (Amersham). After blocking with TBS-T buffer $[20 \mathrm{mM}$ Tris $(\mathrm{pH}$ 7.4), $150 \mathrm{mM} \mathrm{NaCl}, 0.1 \%$ Tween 20] containing 5\% skim milk, the membranes were incubated with primary and secondary antibodies. The membranes were then washed with TBS-T buffer and visualized with ECL Western blotting detection reagents (Amersham). The density of each band was determined with a fluorescence scanner (LAS 3000, Fuji Film, Tokyo, Japan) and analyzed with Multi Gauge V3.0 software.

\section{Statistical analysis}

Experiments were repeated at least 3 times with consistent results. Unless otherwise stated, data are expressed as the mean \pm SD. ANOVA was used to compare the experimental groups with the control; whereas comparisons among multiple groups were performed using a Tukey's multiple comparison tests. Results were statistically significant at $\mathrm{p}<0.05$.

\section{Results}

Salinomycin changes the genome-wide expression in PC-3 prostate cancer cells

An advanced prostate cancer cell line, PC-3 cells were cultivated in the absence or presence of $1.33 \mu \mathrm{M}$ salinomycin for $48 \mathrm{~h}$, followed by gene expression profiling. The gene expression data were compared in order to identify the differentially expressed genes between absence and presence of salinomycin treated group. The Agilent Feature Extraction software 9.3.2.1 contains 44,000 probe sets according to the manufacturer. Among these transcripts, 4,852 probe sets were detected as over 2-fold changed in both absence and presence salinomycin. Of all the present transcripts, 2,541 genes were up-regulated and 2,311 genes were down-regulated (Supplementary Figure 1). We analyzed the changed genes using the DAVID Gene Ontology (GO) resource (http://david.abcc.ncifcrf.gov/) and grouped them into enriched broad categories using a term of Biological Process [27].

\section{Salinomycin induces $G_{1}-$ phase cell cycle arrest in PC-3 cells}

To confirm the cell cycle arrest related gene profiling, we subsequently analyzed cell cycle progression in salinomycin-exposed PC-3 cells using flow cytometry after propidium iodide (PI) staining. Treatment with salinomycin for $48 \mathrm{~h}$ in dose-dependent manner resulted in the accumulation of cells in the $G_{0} / G_{1}$ phase (Figure $1 A$ ). In the presence of 1.33 and $4.00 \mu \mathrm{M}$ of salinomycin, the proportion of cells in $G_{0} / G_{1}$ phase increased gradually over $50 \%$ (Figure $1 B$ ). The proportion of cells in $\mathrm{G}_{2} / \mathrm{M}$ phase after $4.00 \mu \mathrm{M}$ salinomycin treatment was reduced under approximately $10 \%$ as compared to almost $20 \%$ of the untreated cells. These results were consistent with previous microarray analysis to show regulatory gene expression involved in $\mathrm{G}_{1} / \mathrm{S}$ transition. This observation is important because the molecular analyses of human cancers have revealed the cell cycle regulators frequently mutated in most common malignancies and inhibition of the cell cycle has been appreciated as a target for the management of cancer.

\section{Salinomycin induces extensive changes at mRNA and protein level implicating cell cycle arrest}

When the over 2-fold changed genes were analyzed by GO software, clusters for cell cycle arrest and apoptosis were enriched unexpectedly. There was a strong enrichment for genes in cell cycle and apoptosis and proliferation (Supplementary Table 2), and the most significantly enriched genes were shown in Tables 1 and 2. In order to validate the accuracy of GO analysis, we randomly picked genes of cell cycle regulators and determined cDNA expression patterns of

A
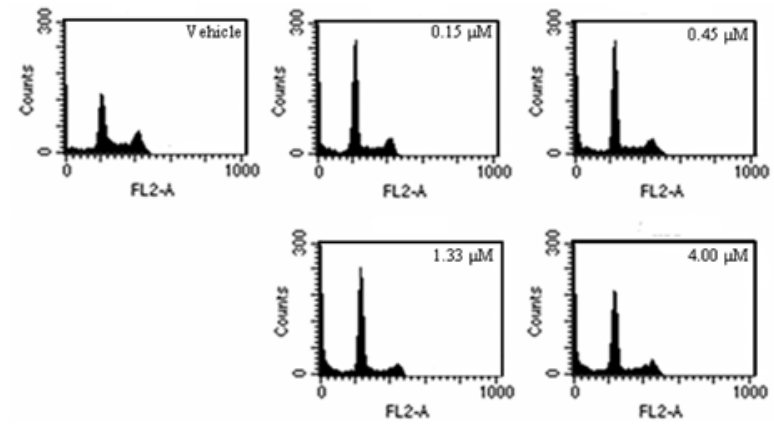

Fl2 $2 x$

B

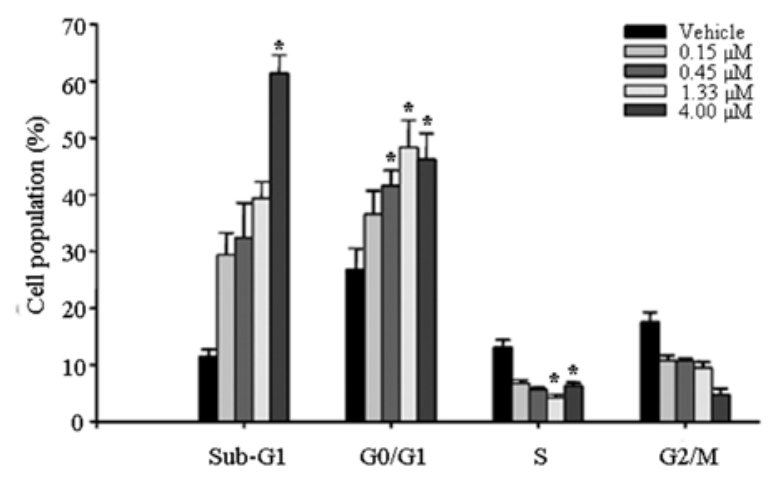

Figure 1: Cell cycle analysis on salinomycin-treated PC-3 cell. (A) Cell cycle arrest. (B) The percentages of cells in each cell cycle phase. Cells were exposed to increasing concentrations $(0-4.00 \mu \mathrm{M})$ of salinomycin for $48 \mathrm{~h}$. After treatment with salinomycin, the cells were fixed with ice-cold $70 \%$ ethanol at $-20^{\circ} \mathrm{C}$ and then stained with propidium iodide $(1 \mathrm{mg} / \mathrm{ml})$, followed by flow cytometery analysis to determine DNA contents. The figures show a representative staining profile for 10,000 cells per experiment. Data are presented as mean $\pm S D$ ( $n=3$, each group). " $p<0.05$ vs. control group. 
Citation: Kim KY, Seo YK, Yu SN, Kim SH, Suh PG, et al. (2013) Gene Expression Profiling from a Prostate Cancer PC-3 Cell Line Treated with Salinomycin Predicts Cell Cycle Arrest and Endoplasmic Reticulum Stress. J Cancer Sci Ther 5: 023-030. doi:10.4172/1948-5956.1000180

\begin{tabular}{|c|c|c|c|}
\hline Gene Symbol & Fold Change & Description & Genbank \\
\hline CDKN2B & 8.61 & cyclin-dependent kinase inhibitor 2B ( $p 15$, inhibits CDK4) & NM_078487 \\
\hline PIM1 & 8.07 & pim-1 oncogene & NM_002648 \\
\hline JUN & 7.30 & jun oncogene & NM_002228 \\
\hline CDKN1C & 6.02 & cyclin-dependent kinase inhibitor 1C (p57, Kip2) & NM_000076 \\
\hline TNFSF15 & 4.58 & tumor necrosis factor (ligand) superfamily, member 15 & NM_005118 \\
\hline BCL2L1 & 4.32 & BCL2-like 1 & NM_001191 \\
\hline VEGFA & 4.28 & vascular endothelial growth factor $A$ & NM_001025366 \\
\hline ARHGEF2 & 4.23 & rho/rac guanine nucleotide exchange factor (GEF) 2 & NM_004723 \\
\hline DUSP1 & 3.59 & dual specificity phosphatase 1 & NM_004417 \\
\hline FOXO4 & 3.32 & forkhead box $\mathrm{O} 4$ & NM_005938 \\
\hline TNFRSF9 & 3.14 & tumor necrosis factor receptor superfamily, member 9 & NM_001561 \\
\hline TXNIP & 3.14 & thioredoxin interacting protein & NM_006472 \\
\hline HMOX1 & 2.98 & heme oxygenase (decycling) 1 & NM_002133 \\
\hline CDKN1A & 2.89 & cyclin-dependent kinase inhibitor 1A (p21, Cip1) & NM_000389 \\
\hline PRUNE2 & 2.81 & prune homolog 2 (Drosophila) & NM_015225 \\
\hline MAGED1 & 2.57 & melanoma antigen family $\mathrm{D}, 1$ & NM_001005333 \\
\hline CDKN2A & 2.53 & cyclin-dependent kinase inhibitor 2A (melanoma, p16, inhibits CDK4) & NM_058197 \\
\hline TNF & 2.44 & tumor necrosis factor (TNF superfamily, member 2) & NM_000594 \\
\hline SOD2 & 2.38 & superoxide dismutase 2 , mitochondrial & NM_001024465 \\
\hline PTPRF & 2.04 & protein tyrosine phosphatase, receptor type, $\mathrm{F}$ & NM_002840 \\
\hline
\end{tabular}

Table 1: List of 2-fold up genes involved in apoptosis, cell cycle and proliferation.

\begin{tabular}{|c|c|c|c|}
\hline Gene Symbol & Fold Change & Description & Genbank \\
\hline BARD1 & 0.27 & BRCA1 associated RING domain 1 & NM_000465 \\
\hline CCNA2 & 0.15 & cyclin A2 & NM_001237 \\
\hline CCNB1 & 0.12 & cyclin B1 & NM_031966 \\
\hline CCNB2 & 0.17 & cyclin B2 & NM_004701 \\
\hline CCND1 & 0.40 & cyclin D1 & NM_053056 \\
\hline CCND3 & 0.46 & cyclin D3 & NM_001760 \\
\hline CCNE1 & 0.22 & cyclin E1 & NM_001238 \\
\hline CDC2 & 0.12 & cell division cycle $2, \mathrm{G} 1$ to $\mathrm{S}$ and $\mathrm{G} 2$ to $\mathrm{M}$ & NM_001786 \\
\hline CDC6 & 0.32 & cell division cycle 6 homolog (S. cerevisiae) & NM_001254 \\
\hline CDC7 & 0.28 & cell division cycle 7 homolog (S. cerevisiae) & NM_003503 \\
\hline CDK10 & 0.45 & cyclin-dependent kinase (CDC2-like) 10 & NM_052987 \\
\hline CDK2 & 0.24 & cyclin-dependent kinase 2 & NM_001798 \\
\hline CDK4 & 1.05 & cyclin-dependent kinase 4 & NM_000075 \\
\hline CDK6 & 0.84 & cyclin-dependent kinase 6 & NM_001259 \\
\hline CDKN2C & 0.32 & cyclin-dependent kinase inhibitor 2C ( $\mathrm{p} 18$, inhibits CDK4) & NM_078626 \\
\hline CDKN3 & 0.14 & cyclin-dependent kinase inhibitor 3 (CDK2-associated dual specificity phosphatase) & NM_005192 \\
\hline CHEK1 & 0.19 & CHK1 checkpoint homolog (S. pombe) & NM_001274 \\
\hline ERBB2 & 0.14 & $\begin{array}{l}\text { v-erb-b2 erythroblastic leukemia viral oncogene homolog } 2 \text {, } \\
\text { neuro/glioblastoma derived oncogene homolog (avian) }\end{array}$ & NM_001005862 \\
\hline RPA1 & 0.37 & replication protein $\mathrm{A} 1,70 \mathrm{kDa}$ & NM_002945 \\
\hline SKP2 & 0.41 & S-phase kinase-associated protein 2 (p45) & NM_032637 \\
\hline
\end{tabular}

Table 2: List of 2-fold down genes involved in apoptosis, cell cycle and proliferation. 
several cell cycle arrest genes with specific primers (Supplementary Table 1 and Figure 2). Cyclins (CCNs) and cyclin dependent kinases (CDKs) are known to be positively regulated. In gene expression profiling, transcripts for CCNA2, CCNB1, CCNB2, CCND1, CCND3 and CCNE1 were down-regulated in gene expression profiling (Table 2). The mRNA levels of cyclin B1 (CCNB1) were slightly downregulated, while cyclin E1 (CCNE1) was obviously down-regulated upon salinomycin treatment, as shown in Figure 2A. Those of cyclin B2 (CCNB2) and cyclin D3 (CCND3), however, were not significantly changed (Figure $2 \mathrm{~A}$ ). The treatment $1.33 \mu \mathrm{M}$ of salinomycin for 6 to 48 $\mathrm{h}$ induced a time-dependent decrease in cyclin A, cyclin D1 and cyclin E protein levels compared to the controls (Figure 2D).

Also, transcripts for CDK1/cell division cycle 2 (CDC2), CDC6, CDC7, CDK10 and CDK2 were down-regulated (Table 2). CDC2/ CDK1, CDK2, CDK4 and CDK6 protein expression were decreased in time dependent manner (Figures $2 \mathrm{~B}$ and $2 \mathrm{E}$ ).

The CDK inhibitor 1A (CDKN1A), CDKN1C, CDKN2A, and CDKN2B, which are known to be negative regulators of cell cycle, were increased in gene expression profiling (Table 1). On the RTPCR, the p15, as CDK4 inhibitor, was increased significantly in time dependent manner, but p16 and p57 were not significantly changes (Figure 2C). Furthermore, p21 $1^{\text {Cip } 1}$ was increased significantly in cells time dependent manner (Figure $2 \mathrm{~F}$ ), consistent with cell arrest at $\mathrm{G}_{1}$ phase by inhibiting CDK4 activation following E2F1 inactivation since the CDK inhibitor, $\mathrm{p} 21^{\mathrm{Cip} 1}$, is a key component in the induction of cell cycle arrest and apoptosis. At $48 \mathrm{~h}$, there was a huge accumulation of the expression of $\mathrm{p} 21^{\mathrm{Cip} 1}$ on salinomycin-treated cells compared to the

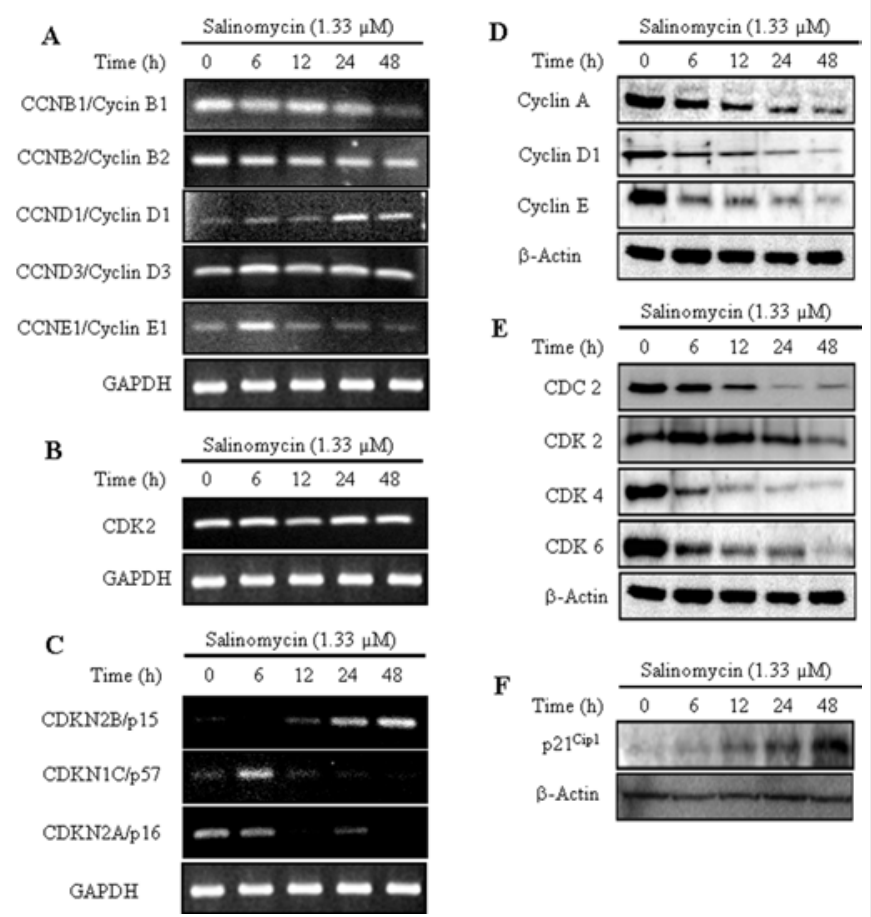

Figure 2: Validation of apoptosis and cell cycle arrest related genes (A, $B, C)$ and proteins (D, E, F) in salinomycin-treated PC-3 cells. (A, D) Cyclin expression, (B, E) Cyclin-dependent kinase expression, (C, F) Cyclindependent kinase inhibitors expression. Semiquantitative RT-PCR analysis for genes expression and Western blot analysis for proteins expression were performed by using PC-3 cells treated with $1.33 \mu \mathrm{M}$ salinomycin for various times. GAPDH and $\beta$-actin were used as an internal control, respectively. control. Since the cell cycle proteins cyclin D1 and CDK4 control G cell cycle progression, whereas cyclin $\mathrm{E}$ and its partner CDK2 dominate cell cycle progression from $G_{1}$ to $S$ phase. These findings, therefore, implicate that salinomycin suppressed cell proliferation in the PC-3 cells through the regulation of the cyclin-protein expression required in $G_{1}$ cell cycle progression, leading to induction of apoptosis.

\section{Salinomycin changes expression of mRNA and proteins involved in ER stress and apoptosis}

ER stress is associated with unfolded protein response activation which is associated with the production of protective chaperones. However, excessive ER stress can cause cellular damage via the activation of the ER-dependent apoptotic pathway. When the genes over 2 -fold changed were analyzed by GO software, clusters for endoplasmic reticulum unfolded protein response, response to unfolded protein and response to endoplasmic reticulum (ER) stress were enriched. There was a strong enrichment for genes in ER stress and UPR (Supplementary Table 3), and the most significantly enriched genes shown in Tables 3 and 4. After incubation with salinomycin, the transcription level of several genes involved in ER stress and UPR were affected. The ER stress sensors inositol-requiring enzyme 1 (IRE1) and downstream targets of these, like XBP-1, were up-regulated, as shown in Table 3. However, as known HSPA4 and HSPA4L, heat shock protein (HSP) 110 family, were down-regulated (Table 4).

As shown in Figure 3, the effects of salinomycin on some genes were involved in ER stress and apoptosis. After salinomycin treatment, phosphorylated eIF2 $\alpha$ (eIF2 $\alpha-P)$, which is a hallmark of ER stress, was found significantly increased time dependent manner (Figure $3 \mathrm{~A})$. Phosphorylation of eIF2 $\alpha$ induces transcription of ATF4 and its downstream targets, like ATF3, CHOP, growth arrest and TRIB3 $[12,28]$ and heme oxygenase 1 (HMOX1) [29]. Moreover, the mRNA and protein levels of CHOP (Figures $3 \mathrm{~A}$ and $3 \mathrm{~B}$ ), TRIB3 (Figure 3A) and ATF4 (Figures 3B and 3D), were also increased. ATF4 is known to induce genes involved in amino acid synthesis and several transcripts involved in amino acid synthesis and transport were also up-regulated (Table 3). Therefore, our results suggest salinomycin induces ER stress and UPR by regulated a variety of chaperone proteins and transcription factors and leads to induction of apoptosis in PC-3 prostate cancer cells.

\section{Discussion}

Several studies have shown that salinomycin inhibits the growth of various cancer cells in vitro and in vivo $[22,24,25]$. We have previously shown that salinomycin induced apoptosis of human prostate cancer cells due to accumulated reactive oxygen species and mitochondrial membrane depolarization [26]. Also, some studies have indicated that salinomycin affects multiple biochemical pathways that might play a role in its apoptosis and growth-limiting effect on diverse type of apoptosis- and chemoresistant- cancer cells. Furthermore, recent preclinical study demonstrated that salinomycin-based various anticancer agents combination treatment could beneficial for development of p-glycoprotein inhibiting drug or radiation therapy $[30,31]$. However, the exact mechanisms underlying salinomycin induced cell death are not yet clear.

Our results showed that salinomycin affects several transcripts involved in cell cycle progression. In microarray data, positive cell cycle regulators, such as cyclin-dependent kinases (CDKs), cyclins, and cell division cycle (CDC), were down-regulated and negative regulators such as CDKs inhibitors were up-regulated. Also, salinomycin affected 
Citation: Kim KY, Seo YK, Yu SN, Kim SH, Suh PG, et al. (2013) Gene Expression Profiling from a Prostate Cancer PC-3 Cell Line Treated with Salinomycin Predicts Cell Cycle Arrest and Endoplasmic Reticulum Stress. J Cancer Sci Ther 5: 023-030. doi:10.4172/1948-5956.1000180

\begin{tabular}{|c|c|c|c|}
\hline Gene Symbol & Fold Change & Description & Genbank \\
\hline ATF4 & 2.18 & activating transcription factor 4 (tax-responsive enhancer element B67) & NM_001675 \\
\hline ATF6 & 1.78 & activating transcription factor 6 & NM_007348 \\
\hline DDIT3 & 6.33 & DNA-damage-inducible transcript 3 & NM_004083 \\
\hline EDEM1 & 3.60 & ER degradation enhancer, mannosidase alpha-like 1 & NM_014674 \\
\hline EIF2A & 1.16 & eukaryotic translation initiation factor $2 \mathrm{~A}, 65 \mathrm{kDa}$ & NM_032025 \\
\hline EIF2AK3 & 4.02 & eukaryotic translation initiation factor 2-alpha kinase 3 & NM_004836 \\
\hline FAM129A & 2.26 & family with sequence similarity 129 , member $A$ & NM_052966 \\
\hline HERPUD1 & 8.78 & homocysteine-inducible, endoplasmic reticulum stress-inducible, ubiquitin-like domain member 1 & NM_014685 \\
\hline HERPUD2 & 2.13 & HERPUD family member 2 & NM_022373 \\
\hline HMOX1/HSP32 & 2.98 & heme oxygenase (decycling) 1 & NM_002133 \\
\hline HSPA1A & 2.31 & heat shock $70 \mathrm{kDa}$ protein $1 \mathrm{~A}$ & NM_005345 \\
\hline HSPA1L & 2.29 & heat shock $70 \mathrm{kDa}$ protein 1 -like & NM_005527 \\
\hline HSPA5 & 3.54 & heat shock $70 \mathrm{kDa}$ protein 5 (glucose-regulated protein, $78 \mathrm{kDa}$ ) & NM_005347 \\
\hline IRE1/ERN1 & 4.06 & endoplasmic reticulum to nucleus signalling 1 & NM_001433 \\
\hline SEC63 & 2.15 & SEC63 homolog (S. cerevisiae) & NM_007214 \\
\hline SQSTM1 & 4.44 & sequestosome 1 & NM_003900 \\
\hline TRIB3 & 2.07 & tribbles homolog 3 (Drosophila) & NM_021158 \\
\hline TXNDC4 & 2.03 & thioredoxin domain containing 4 (endoplasmic reticulum) & NM_015051 \\
\hline XBP1 & 2.66 & X-box binding protein 1 & NM_005080 \\
\hline
\end{tabular}

Table 3: List of 2-fold up genes involved in ER stress and UPR.

\begin{tabular}{|l|c|l|l|}
\hline Gene Symbol & Fold Change & Description & Genbank \\
\hline ATG10 & 0.45 & ATG10 autophagy related 10 homolog (S. cerevisiae) & NM_031482 \\
\hline HSPA4 & 0.38 & heat shock 70kDa protein 4 & NM_002154 \\
\hline HSPA4L & 0.27 & heat shock 70kDa protein 4-like & NM_014278 \\
\hline TOR1A & 0.41 & torsin family 1, member A (torsin A) & NM_000113 \\
\hline
\end{tabular}

Table 4: List of 2-fold down genes involved in ER stress and UPR.

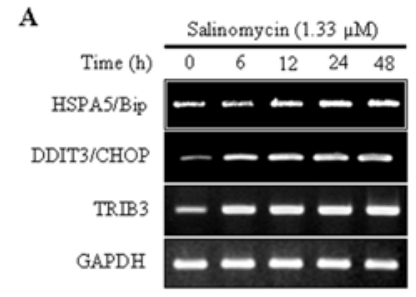

B

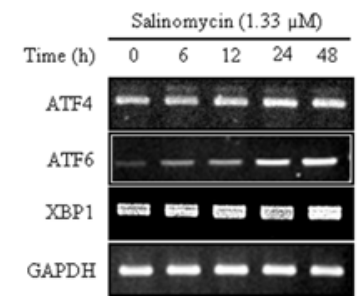

C

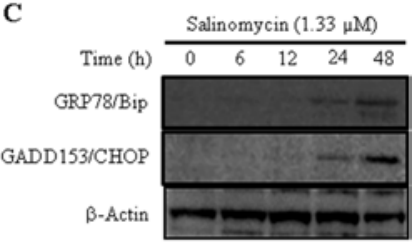

D

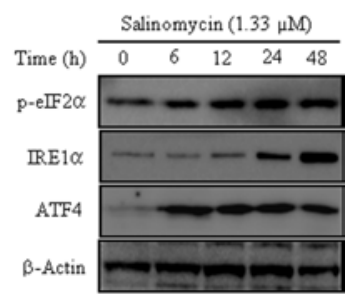

Figure 3: Validation of apoptosis and ER stress/UPR related genes ( $A$, B) and proteins(C, D) in salinomycin-treated PC-3 cells. (A, C) ER stress sensors expression. (B, D) ER stress related transcript factors expression. Semiquantitative RT-PCR analysis for genes expression and Western blot analysis for proteins expression were performed by using PC-3 cells treated with $1.33 \mu \mathrm{M}$ salinomycin for various times. GAPDH and $\beta$-actin were used as an internal control, respectively.

several cell cycle transcripts and proteins like CDKs, cyclins and CDKs inhibitors and arrests significantly the cells in $\mathrm{G}_{1}$ phase of the cell cycle. However, CDK4 and CDK6 did not change mRNA levels in microarray analysis but protein expression was confirmed to be reduced in a time-dependent manner. Salinomycin-induced cell cycle arrest might be associated with reduction of cyclins $\mathrm{E}$ and $\mathrm{B}, \mathrm{CDK} 2$ and CDK4. Furthermore, several studies reported that expression of p $21^{\text {cip1 }}$ was increased by p53 activation [9]. But salinomycin induced p2 $1^{\text {cip } 1}$ activation in even p53-independent PC-3 cells. These results indicated that one of the mechanisms which salinomycin may regulate is the proliferation of cancer cells by inhibiting cell cycle progression.

This is the first study demonstrating that salinomycin induces endoplasmic reticulum (ER) stress and substantial activation of ER stress-dependent gene expression in a prostate cancer cell. Transcripts involved in ER stress and downstream of all three ER stress sensors, such as inositol-requiring enzyme 1 (IRE1), X-box binding protein 1 (XBP1), activating transcription factor 4 (ATF4) and ATF6 were found to be increased after treating PC-3 cells with salinomycin. Also, the increased expression of heat shock proteins (HSPs) indicated that the cells try to increase their protein folding capacity. The up-regulation of ER degradation enhancer, mannosidase alpha-like 1 (EDEM1) and sequestosome 1(SQSTM1), proteasomal and ubiquitinrelated 
Citation: Kim KY, Seo YK, Yu SN, Kim SH, Suh PG, et al. (2013) Gene Expression Profiling from a Prostate Cancer PC-3 Cell Line Treated with Salinomycin Predicts Cell Cycle Arrest and Endoplasmic Reticulum Stress. J Cancer Sci Ther 5: 023-030. doi:10.4172/1948-5956.1000180

transcripts indicated activation of ER-associated degradation (ERAD). The eukaryotic translation initiation factor 2 alpha (eIF2 $\alpha$ ) kinase 3 (EIF2AK3/PERK) branch of unfolded protein response (UPR) was found to be activated, supported by the increased protein level of p-eIF2 $\alpha$ and ATF4, as well as up-regulation of several downstream targets of ATF4, such as ATF3, ASNS, DNA-damage-inducible transcript 3 (DDIT3/CHOP) and tribbles homolog 3 (TRIB3) at mRNA level, which are known to link ER stress to ER stress induced cell death. During ER stress, activation of the PERK-dependent pathway leads to phosphorylation of eIF2 $\alpha[32,33]$. Phosphorylation of this protein increases translation of a number of mRNAs, one of which is ATF4, and results in the reduction of ER protein load [33,34]. Our observations of salinomycin-induced increases in the expression of ATF4 protein and transcript were consistent with prior reports that this transcription factor is induced under conditions of ER stresses. The expression of $\mathrm{CHOP}$ in response to stress is regulated at the transcriptional level through the transcription factor ATF2, 4 and 6 [17]. Numerous pro-apoptotic and anti-apoptotic genes, including Bcl-2, GADD34, and TRIB3, were regulated by CHOP, which is a transcription factor with a well-established role in ER stress, particularly in the induction of apoptosis [35]. CHOP directly binds the promoter of TRIB3 gene and up-regulates its expression, which results in apoptosis via inhibition of AKT activation [35]. Intriguingly, TRIB3 also regulates CHOP expression through negative feedback [36]. Also, CHOP has been associated with mitochondrial stress induced by accumulation of unfolded proteins [37]. Originally we reported that salinomycin induced the apoptosis of prostate cancer cell lines through accumulated reactive oxygen species (ROS) and mitochondrial membrane depolarization [26]. At this time, analysis of complete gene profiling in our cDNA microarray was consistent with our previous study. That is to say, salinomycin induced several oxidation stressand mitochondrial dysfunction-related genes expression (data not shown) but, in this study, we didn't research the genes expression related with ROS and mitochondrial membrane potentials. Because our data implicate that salinomycin seems to cause ER stress through mitochondrial stress and oxidative stress, along with our previous data [26], we will handle those kinds of genes expression to confirm the cDNA microarray data in next study.

In summary, the present study demonstrated that a dose of salinomycin causes changes in the transcription of genes or induction of proteins that are involved in the regulation of an array of cellular functions. These include activation of genes that participate in cell cycle arrest and cellular responses to ER stresses, observing a gene expression analysis using microarray technology, which lead to induction of apoptosis. Additional studies are required to evaluate these cellular phenomena further.

\section{Acknowledgments}

This research was supported by Basic Science Research Program through the National Research Foundation of Korea (NRF) funded by the Ministry of Education, Science and Technology (2012R1A1A2022587).

\section{References}

1. Jemal A, Bray F, Center MM, Ferlay J, Ward E, et al. (2011) Global cancer statistics. CA Cancer J Clin 61: 69-90.

2. Cho HJ, Yu SN, Kim KY, Sohn JH, Oh H, et al. (2009) Screening and purification of an anti-prostate cancer compound, deoxypodophyllotoxin, from Anthriscus sylvestris Hoffm. J Life Science 19: 9-14.

3. Hahn WC, Weinberg RA (2002) Modelling the molecular circuitry of cancer. Nat Rev Cancer 2: 331-341.
4. Nowak MA, Komarova NL, Sengupta A, Jallepalli PV, Shih leM, et al. (2002) The role of chromosomal instability in tumor initiation. Proc Natl Acad Sci U S A 99:16226-16231.

5. Srivastava RK, Chen Q, Siddiqui I, Sarva K, Shankar S (2007) Linkage of curcumin-induced cell cycle arrest and apoptosis by cyclin-dependent kinase inhibitor p21(/WAF1/CIP1). Cell Cycle 6: 2953-2961.

6. Sherr CJ, Roberts JM (2004) Living with or without cyclins and cyclin-dependent kinases. Genes Dev 18: 2699-2711.

7. Ghiani C, Gallo V (2001) Inhibition of cyclin E-cyclin-dependent kinase 2 complex formation and activity is associated with cell cycle arrest and withdrawal in oligodendrocyte progenitor cells. J Neurosci 21: 1274-1282.

8. Vermeulen K, Van Bockstaele DR, Berneman ZN (2003) The cell cycle: a review of regulation, deregulation and therapeutic targets in cancer. Cell Prolif 36: 131-149.

9. Chen WJ, Chang CY, Lin JK (2003) Induction of G1 phase arrest in MCF human breast cancer cells by pentagalloylglucose through the down-regulation of CDK4 and CDK2 activities and up-regulation of the CDK inhibitors p27(Kip) and p21(Cip). Biochem Pharmacol 65: 1777-1785

10. Ohtsubo M, Theodoras AM, Schumacher J, Roberts JM, Pagano M (1995) Human cyclin E, a nuclear protein essential for the G1-to-S phase transition. Mol Cell Biol 15: 2612-2624.

11. Agarwal R (2000) Cell signaling and regulators of cell cycle as molecula targets for prostate cancer prevention by dietary agents. Biochem Pharmaco 60: 1051-1059

12. Ron D, Walter $P$ (2007) Signal integration in the endoplasmic reticulum unfolded protein response. Nat Rev Mol Cell Biol 8: 519-529.

13. Görlach A, Klappa P, Kietzmann T (2006) The endoplasmic reticulum: folding calcium homeostasis, signaling, and redox control. Antioxid Redox Signal 8 : 1391-1418.

14. Harding HP, Zhang Y, Bertolotti A, Zeng H, Ron D (2000) Perk is essential fo translational regulation and cell survival during the unfolded protein response. Mol Cell 5: 897-904.

15. Schröder M, Kaufman RJ (2005) ER stress and the unfolded protein response. Mutat Res 569: 29-63.

16. Szegezdi E, Logue SE, Gorman AM, Samali A (2006) Mediators of endoplasmic reticulum stress-induced apoptosis. EMBO Rep 7: 880-885.

17. Oyadomari S, Mori M (2004) Roles of CHOP/GADD153 in endoplasmic reticulum stress. Cell Death Differ 11: 381-389.

18. McCullough KD, Martindale JL, Klotz LO, Aw TY, Holbrook NJ (2001) Gadd153 sensitizes cells to endoplasmic reticulum stress by down-regulating $\mathrm{Bcl} 2$ and perturbing the cellular redox state. Mol Cell Biol 21: 1249-1259.

19. Puthalakath H, O'Reilly LA, Gunn P, Lee L, Kelly PN, et al. (2007) ER stress triggers apoptosis by activating BH3-only protein Bim. Cell 129: 1337-1349.

20. Miyazaki Y, Shibuya M, Sugawara H, Kawaguchi O, Hirsoe C (1974) Salinomycin, a new polyether antibiotic. J Antibiot (Tokyo) 27: 814-821.

21. Danforth HD, Ruff MD, Reid WM, Miller RL (1977) Anticoccidial activity of salinomycin in battery raised broiler chickens. Poult Sci 56: 926-932.

22. Gupta PB, Onder TT, Jiang G, Tao K, Kuperwasser C, et al. (2009) Identification of selective inhibitors of cancer stem cells by high-throughput screening. Cell 138: 645-659.

23. Naujokat C, Fuchs D, Opelz G (2010) Salinomycin in cancer: A new mission for an old agent. Mol Med Report 3: 555-559.

24. Fuchs D, Heinold A, Opelz G, Daniel V, Naujokat C (2009) Salinomycin induces apoptosis and overcomes apoptosis resistance in human cancer cells. Biochem Biophys Res Commun 390: 743-749.

25. Fuchs D, Daniel V, Sadeghi M, Opelz G, Naujokat C (2010) Salinomycin overcomes $A B C$ transporter-mediated multidrug and apoptosis resistance in human leukemia stem cell-like KG-1a cells. Biochem Biophys Res Commun 394: 1098-1104.

26. Kim KY, Yu SN, Lee SY, Chun SS, Choi YL, et al. (2011) Salinomycin-induced apoptosis of human prostate cancer cells due to accumulated reactive oxygen species and mitochondrial membrane depolarization. Biochem Biophys Res Commun 413: 80-86. 
Citation: Kim KY, Seo YK, Yu SN, Kim SH, Suh PG, et al. (2013) Gene Expression Profiling from a Prostate Cancer PC-3 Cell Line Treated with Salinomycin Predicts Cell Cycle Arrest and Endoplasmic Reticulum Stress. J Cancer Sci Ther 5: 023-030. doi:10.4172/1948-5956.1000180

27. Dennis G Jr, Sherman BT, Hosack DA, Yang J, Gao W, et al. (2003) DAVID: Database for Annotation, Visualization, and Integrated Discovery. Genome Bio 4: P3.

28. Schroder M (2008) Endoplasmic reticulum stress responses. Cell Mol Life Sci 65: 862-894.

29. He CH, Gong P, Hu B, Stewart D, Choi ME, et al. (2001) Identification of activating transcription factor 4 (ATF4) as an Nrf2-interacting protein. Implication for heme oxygenase-1 gene regulation. J Biol Chem 276: 20858-20865.

30. Kim JH, Chae M, Kim WK, Kim YJ, Kang HS, et al. (2011) Salinomycin sensitizes cancer cells to the effects of doxorubicin and etoposide treatment by increasing DNA damage and reducing p21 protein. Br J Pharmacol 162: 773-784.

31. Park SH, Wang X, Liu R, Lam KS, Weiss RH (2008) High throughput screening of a small molecule one-bead-one-compound combinatorial library to identify attenuators of p21 as chemotherapy sensitizers. Cancer Biol Ther 7: 20152022.

32. Teske BF, Wek SA, Bunpo P, Cundiff JK, McClintick JN, et al. (2011) The elF2 kinase PERK and the integrated stress response facilitate activation of ATF6 during endoplasmic reticulum stress. Mol Biol Cell 22: 4390-4405.
33. Diakogiannaki E, Welters HJ, Morgan NG (2008) Differential regulation of the endoplasmic reticulum stress response in pancreatic beta-cells exposed to long-chain saturated and monounsaturated fatty acids. J Endocrinol 197: 553 563.

34. Yan Y, Gao YY, Liu BQ, Niu XF, Zhuang Y, et al. (2010) Resveratrol-induced cytotoxicity in human Burkitt's lymphoma cells is coupled to the unfolded protein response. BMC Cancer 10: 445 .

35. Bromati CR, Lellis-Santos C, Yamanaka TS, Nogueira TC, Leonelli M, et al. (2011) UPR induces transient burst of apoptosis in islets of early lactating rats through reduced AKT phosphorylation via ATF4/CHOP stimulation of TRB3 expression. Am J Physiol Regul Integr Comp Physiol 300: R92-R100.

36. Ohoka N, Yoshii S, Hattori T, Onozaki K, Hayashi H (2005) TRB3, a novel ER stress-inducible gene, is induced via ATF4-CHOP pathway and is involved in cell death. Embo J 24: 1243-1255.

37. Aldridge JE, Horibe T, Hoogenraad NJ (2007) Discovery of genes activated by the mitochondrial unfolded protein response (mtUPR) and cognate promote elements. PLoS One 2: e874. 